\title{
Investment in deepwater oil and gas exploration projects: a multi-factor analysis with a real options model
}

\author{
Xin-Hua Qiu ${ }^{1} \cdot$ Zhen Wang $^{2} \cdot$ Qing Xue $^{1}$
}

Received: 23 September 2014/Published online: 18 July 2015

(c) The Author(s) 2015. This article is published with open access at Springerlink.com

\begin{abstract}
Deepwater oil and gas projects embody high risks from geology and engineering aspects, which exert substantial influence on project valuation. But the uncertainties may be converted to additional value to the projects in the case of flexible management. Given the flexibility of project management, this paper extends the classical real options model to a multi-factor model which contains oil price, geology, and engineering uncertainties. It then gives an application example of the new model to evaluate deepwater oil and gas projects with a numerical analytical method. Compared with other methods and models, this multi-factor real options model contains more project information. It reflects the potential value deriving not only from oil price variation but also from geology and engineering uncertainties, which provides more accurate and reliable valuation information for decision makers.
\end{abstract}

Keywords Investment decision - Real options - Multifactor model · Option pricing · Deepwater oil and gas

\section{Introduction}

Deepwater petroleum investment has attracted much attention as offshore oil and gas resources are making up a large portion of worldwide energy potentials. However,

Zhen Wang

wangzhen@cup.edu.cn

1 School of Business Administration, China University of Petroleum, Beijing 102249, China

2 Academy of Chinese Energy Strategy, China University of Petroleum, Beijing 102249, China

Edited by Xiu-Qin Zhu due to the marine geographical environment, deepwater oil, and gas development projects contain higher geology and engineering risk than onshore or continental shelf projects. This situation increases the total amount of investment and the complexity of decision-making process. On one hand, the volatility of oil price causes more flexibility value for the deepwater projects which demand a longer duration for exploration. On the other hand, the technical risk of deepwater projects under development is much higher than that of onshore or continental shelf ones, and the effects of engineering and technological uncertainties on the value of deepwater projects are more significant. Under this background, the traditional theory of net present value cannot provide sufficient reliable reference for the decision making of deepwater oil and gas investment, because the value of flexibility from the uncertainties in oil price, engineering, and technology cannot be measured under the rigid assumptions. Therefore, the real options method based on uncertainty analysis is more suitable to evaluate deepwater oil and gas projects than the conventional ones.

The real options theory, originating from the financial option, regards the value from management flexibility as an option which could generate revenue. Myers (1977) analyzed the value of real options of additional investment opportunities for the first time. Since then, the flexibility value of real investment has received ongoing attention. Dixit and Pindyck (1994) summarized the research achievements of the real options theory and presented a systematic exposition of its construction and application. Firstly, they described the statistical characteristics of the uncertainty factor which influences the cash flow significantly. Secondly, they determined the functional relationship between uncertainty factors and the revenue and established the equation by non-arbitrage portfolio. 
Thirdly, they derive the equation for the real options model based on the assumptions and boundary conditions.

Since Brennan and Schwartz (1985) and Paddock et al. (1988) evaluated natural resources investment by adopting the real options method, research using the real options method has gradually increased. Dias (2004) presented an overview of real options models to evaluate investments in petroleum exploration and production projects. He pointed out that oil price was the only random variable in almost all the real option models and empirical studies, and other technical factors are assumed to be constant which could be obtained from engineers before the evaluation. In his review, a petroleum project was considered as a long-term investment and production process, during which the fluctuation of oil price could influence its economic value significantly. It could increase the flexibility value by adjusting production according to the oil price fluctuation. Due to the importance and financial attribute of oil price, simulation for the stochastic characteristics of oil price was a focus in real option research.

However, factors affecting the flexibility value of oil and gas projects are not limited to oil price, especially in the case of deepwater oil and gas exploration and development projects. The flexibility of geological understanding and engineering technology also has an important influence on the projects. The geological and technological information will be more accurate with increasing investment. The investors could make better decisions with the additional knowledge to realize flexibility value which may be ignored by the net present value method. In the theory of real options, the additional information and flexible management are valuable. If the flexible value of an underlying project is larger than its required investment, the project will be profitable. In order to evaluate the comprehensive flexibility value, a multi-factor real options model should be established with geological and technological factors in addition to the price factor.

Attempts to set up a multi-factor real options model have been made recently. Cortazar et al. (2001) added the information of geology and technology to the model of Brennan and Schwartz (1985) to evaluate a copper mine, but the study was not intensive. Cortazar et al. (2001) did not analyze the relationship between the information uncertainty and the flexibility value, and failed to describe the establishment or application of the model. The uncertainty factors and flexibility need further investigation. Fan and Zhu (2010) built a multi-factor real options model and applied it to an oil investment decision. However, the research did not consider the two important factors of geological and technological uncertainties. It introduced the exchange rate and resource tax rate to the model, none of which has a significant effect on the flexibility value for deepwater oil and gas projects. They proposed to adjust oil price to exchange rate and tax rate, and then substituted the volatility of oil price in the conventional real options model for integration of the three volatilities. However, the integration is meaningless because their integrated factor has no difference from a single factor in essence. Furthermore, the tax rate does not have a stochastic characteristic. Schmit et al. (2011) built a two factors real options model to estimate the influence of U.S. ethanol policy on plant investment decisions. Similarly, this research focused on the financial aspect only, which defined the two variables as revenue and cost, ignoring the important influence from technology and engineering.

Our multi-factor real options model and its application to deepwater projects will make several contributions. In the aspect of random factors, we analyze three of the most important factors: oil price, geological information, and engineering information, based on the characteristics of deepwater oil and gas projects. We also integrate the three factors based on the stochastic process theory. In the aspect of real options model, we extend the single-factor model with geological and technical factors to better describe the flexibility value of deepwater oil and gas projects on the basis of the integration model, because the partial differential equation for three factors is too complex to be solved. In the aspect of application, we provide an example to show the practical significance of key parameters and introduce the method of parameter assignment. We also apply the real options model to value a deepwater project under a typical production-sharing contract.

This paper is organized as follows: In the second section, we will describe and integrate the variables with stochastic process theory. In Sect. 3, the multi-factor real options model will be established based on the integration model and the non-arbitrage approach. In Sect. 4, we will discuss the parameter assignment. In Sect. 5, we will apply the model to a deep water oil and gas project and analyze the optimal investment decision. Section 6 is the conclusions.

\section{Three factors affecting the value of flexibility in deepwater oil and gas projects}

Considering the characteristics of marine geographical environments, the flexibility value of deepwater oil and gas projects is determined not only by the volatility of oil price but also by the uncertainty of geology and engineering technology. If the exploration and development scheme is adjusted based on the additional information, the economy value of project could be increased.

The flexibility value of geology conditions implies the unremitting objectives of minimization of investment and maximization of profit since the geology information 
updated as the project proceeds helps make the investment budget more precise. In the oil and gas industry, the investment in exploration gives investors priority over next stage's activities. So these investors have more prominent opportunities due to their information privilege. The flexibility of technology implies potential cost savings and production increases in the process of exploration and production with the uncertainties being gradually clarified and problems solved. On the other hand, under the background of whole block development, the flexibility of technology implies the value maximization for all projects located in the same area since investors could properly design the overall development program and share the facilities among different projects in that area. Besides, the flexibility value of oil price changes could never be neglected since deep water oil and gas development projects always take many years. Investors and their management team can adjust their actual production according to the price at the time under specific technology and engineering conditions, so as to realize the best economic value of oil and gas reserves.

Geological conditions, technologies, and oil price are the main factors that affect the real options value of deepwater oil and gas projects. This work aims to study these three factors first, and build a multi-factor real options model on such basis.

There are two requirements in simulation of random factors. Firstly, the model should be concise enough for practical use and could accurately render the dynamic characteristics of random factors since the purpose of simulation is to construct financial models and realize necessary computation rather than to make predictions on future situation. Secondly, many financial models are built on the basis of Ito's lemma by now, however the random factor models are also needed to follow Brownian movements as basic variables do (Itō 2010, 2011).

\subsection{Oil price simulation}

There has been a lot of research conducted on simulation and prediction of oil prices because of the importance of petroleum in the world economy and international relationships. It has been shown that the fluctuation of oil price follows a random walk process with sudden increases or jumps at certain periods. Dixit and Pindyck (1994) described the oil price with several models. They pointed out that the geometric Brownian motion (GBM) should be a foundational model and the mean reverting model could describe the stochastic characteristics of oil price more accurately since oil price fluctuated around the cost of oil production which was stable. But the difficulty and the cost of oil exploitation have increased rapidly with soaring demand during the past two decades, and this change has been reflected in the oil price fluctuation (see Fig. 1), so the mean reverting model is not as accurate to describe the characteristics of oil price.

Compared with the mean reverting model, GBM is more appropriate to embody oil price movements, as GBM conforms to both the stochastic characteristics of oil prices and the two requirements mentioned above.

Then, the simulation model of oil price will be:

$\mathrm{d} P_{t}=\mu P_{t} \mathrm{~d} t+\sigma_{P} P_{t} \mathrm{~d} W_{t}$,

where $P_{t}$ is the oil price at time $t, W_{t}$ is a Wiener process, $\mu$ and $\sigma_{P}$ are constants.

Assuming an initial price of $P_{0}$, use the Ito stochastic integral to solve the equation and we will get the following:

$P_{t}=P_{0} \exp \left(\left(\mu-\frac{\sigma_{P}^{2}}{2}\right) t+\sigma_{P} W_{t}\right)$.

\subsection{Simulation of technological and geological factors in engineering}

Technological and geological factors in engineering can substantially affect the overall economic value of deepwater oil and gas exploration projects as economic factors on the product market do, and must be included in the evaluation model.

Deepwater exploration technology is rapidly evolving. Specialists and technicians are exploring better methods to describe geology, technological conditions, and risks in the seabed. Their ideas and models can be quite different, and most of them end up in describing various geological and technological factors in the form of probabilities. Therefore, probability theory can be used to study the geological and technological uncertainties in the evaluation model for deepwater oil and gas exploration projects. However, most technological models in engineering involve various parameters, which are complicated and confidential, and cannot be directly used in economic models. Thus the model with geological and technological uncertainties must be designed with comprehensive study of technological methods in engineering to meet the requirements of an evaluation model.

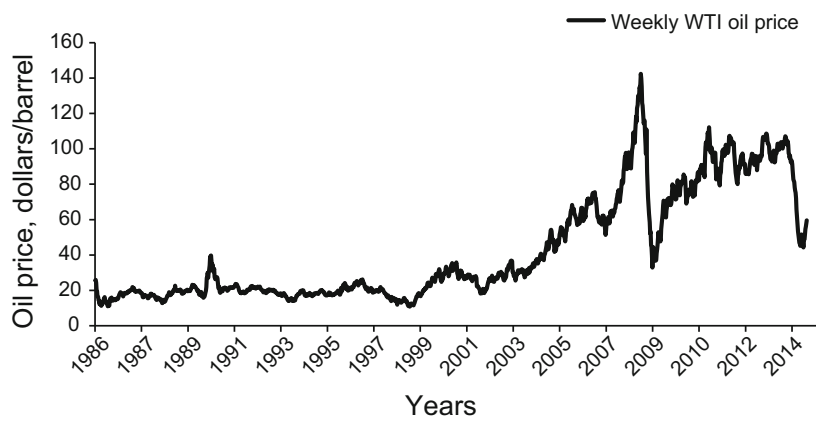

Fig. 1 The fluctuation of WTI oil price 
All the random variables in a stochastic system can be described by a stochastic process. According to research findings (Clapp and Stibolt 1991), engineering and technology data follow normal distribution with certain features, and can be described by a stochastic differential equation. Engineering technology covers a wide range of factors with correlations among some of them, and it is impractical to clarify each of them in an economic model. Thus geological and technological factors in engineering will be taken as one comprehensive factor in simulation and analysis.

We hereby define a one dimension geology technology factor $G$, which follows Brownian movement with zero drift and constant volatility.

$\mathrm{d} G=G \sigma_{\mathrm{G}} \mathrm{d} W_{\mathrm{G}}$,

where $\sigma_{G}$ is volatility, $\mathrm{d} W_{G}$ is the standard Wiener increment.

\subsection{Variables integration}

The above analysis and treatment for oil prices and geological and technological factors with a stochastic model is to investigate how to put the uncertain technological factors separately and directly into the evaluation model, so as to provide precise evaluation results for deepwater oil and gas assets. However, it is over sophisticated to put both factors $P$ and $G$ into a proper model together with the application of Ito's lemma. Therefore factor $P$ and factor $G$ will be technically integrated into one factor to build a three-factor model (Itō 2010).

Both oil price $(P)$ and geology technology $(G)$ impact on the value of deepwater oil and gas projects, where $P$ is mainly affected by market dynamics, and $G$ affected by geological conditions under the sea floor and by achievements in technological development. Therefore assume factors $P$ and $G$ are independent, which means:

$\mathrm{d} W_{P} \mathrm{~d} W_{G}=0$

and let

$Z \equiv F(P, G)$.

According to Ito's lemma, we substitute Eq. (1) and Eq. (3) into Eq. (5) and get:

$$
\begin{aligned}
\mathrm{d} Z= & \left(F_{P} P \mu+\frac{1}{2} F_{P P} P^{2} \sigma_{P}^{2}+\frac{1}{2} F_{G G} G^{2} \sigma_{G}^{2}\right) \mathrm{d} t \\
& +F_{P} P \sigma_{P} \mathrm{~d} W_{P}+F_{G} G \sigma_{G} \mathrm{~d} W_{G} .
\end{aligned}
$$

In order to make Eq. (6) solvable and ensure the effectiveness of the evaluation model, we apply the principle of value additivity of stochastic process by Itō's (2010) and get:
$Z \equiv F(P, G)=P G$.

Given that factors $P$ and $G$ following standard Wiener process, and they both are independent and unrelated incremental variables, Eq. (7) is correct according to Ito's theory and the two stochastic processes can be superimposed to get:

$\frac{\mathrm{d} Z}{Z}=\mu \mathrm{d} t+\sigma_{\mathrm{P}} \mathrm{d} W_{\mathrm{P}}+\sigma_{\mathrm{G}} \mathrm{d} W_{\mathrm{G}}$.

Hence the new variable $Z$ embodies the same drift rate with oil price $P$ but larger volatility than $P$ :

$\sigma_{Z}=\sqrt{\sigma_{P}^{2}+\sigma_{G}^{2}}$

\section{Modeling}

\subsection{Hypothesis in modeling}

Actual economic problems are far more diversified and complicated. A series of hypothesis are established in the light of the problems' particularity and research targets for simulation and computation, so as to better describe and solve problems with mathematic modeling. The fundamental hypotheses in real options modeling for deepwater oil and gas exploration projects are as follows:

(1) Oil price $P$ follows GBM process, and its convenience yield is the function of oil price;

(2) The geological technological variables follow Brownian movement;

(3) Investment return $r$ is known and constant;

(4) The reproduction cost of the investment portfolio is negligible;

(5) The real options value $V(Z, t)$ in the form of variable $Z$ and time $t$ is second order differentiable, and follows Ito's lemma;

(6) The compound option is perpetual since oil and gas exploration contracts last for many years.

\subsection{Model establishment}

The evaluation model is established on the basis of noarbitrage portfolio theory. Assume $F(Z, \tau)$ is the price function of petroleum futures bought at time $t$ with expiration time at $T$, where $\tau=T-t$. According to Ito's lemma, the instant yield of the futures is:

$\mathrm{d} F=\left(-F_{\tau}+\frac{1}{2} F_{Z Z} \sigma^{2} Z^{2}\right) \mathrm{d} t+F_{Z} \mathrm{~d} Z$,

where $F_{Z}$ and $F_{Z Z}$ are first and second order partial derivatives. 
And with Eq. (7) we have:

$F_{P}=F_{Z} \times G \quad F_{P P}=F_{Z Z} \times G^{2}$

Then we generalize such an investment portfolio: An investor goes long on one unit of crude oil in the spot market and goes short on $\left(F_{P}\right)^{-1}$ unit of crude oil as underlying asset in the future market. Suppose no dividend is to be paid. According to Eqs. (10 and 11), the rate of return for this portfolio is:

$$
\begin{aligned}
\frac{\mathrm{d} P}{P} & +\frac{C(Z) \mathrm{d} t}{P}-\left(P F_{P}\right)^{-1} \mathrm{~d} F \\
& =\left(P F_{P}\right)^{-1}\left[F_{P} C(Z)-\frac{1}{2} F_{P P} \sigma^{2} P^{2}+F_{\tau}\right] \mathrm{d} t,
\end{aligned}
$$

where $C(Z)$ indicates convenience yield. Under the no-arbitrage principle of efficient market, the investment return of above portfolio equals the market return, which means:

$\frac{1}{2} F_{P P} \sigma^{2} P^{2}+F_{P}(r P-C)-F_{\tau}=0$.

The boundary condition is:

$F(P, G, 0)=P$.

With Eq. (10), Eq. (11), and Eq. (8) we have:

$\mathrm{d} F=F_{P}[P(\mu-r)+C] \mathrm{d} t+F_{P} P \sigma \mathrm{d} z$.

Deepwater oil and gas exploration involves special risks and tremendous investments, and the economic value is mainly affected by oil price $P$, geology technology $G$, accumulative investment $I$, and time $t$. Taking $V$ for the value of the petroleum asset, and with Eq. (7), we get:

$V \equiv V(G, P, I, t)=V(Z, I, t)$.

With Ito's lemma Eq. (16) is changed into:

$\mathrm{d} V=V_{Z} \mathrm{~d} Z+V_{I} \mathrm{~d} I+V_{t} \mathrm{~d} t+\frac{1}{2} V_{Z Z}(\mathrm{~d} Z)^{2}$.

Let $q$ be per unit investment, $\lambda$ the average income tax rate, $\gamma$ the rate of success in exploration, thus the after-tax cash flow of the exploration project will be:

$\gamma V-q-\lambda V$.

In order to get the partial differential equation of project value $(V)$, we build another investment portfolio: buy one unit of oil asset and sell the same unit of oil futures, then the investment return will be:

$$
\begin{aligned}
\mathrm{d} V & +[\gamma V-q-\lambda V] \mathrm{d} t-\left(V_{P} / F_{P}\right) \mathrm{d} F \\
& =\frac{1}{2} \sigma^{2} Z^{2} V_{Z Z}-q V_{I}+V_{t}+(r P-C) V_{P}+[\gamma V-q-\lambda V] .
\end{aligned}
$$

In light of the no-arbitrage principle, the portfolio return is equal to the market return $r_{V}$. With Eq. (11) we have:

$$
\begin{aligned}
& \frac{1}{2} \sigma^{2} Z^{2} V_{Z Z}-q V_{I}+V_{t}+(r P-C) V_{Z}+q \\
& -(r+\lambda-\gamma) V=0 .
\end{aligned}
$$

Taking deepwater oil and gas exploration projects as perpetual real options, then the operational period $t$ is infinite. When an investor is operating one project, he also keeps seeking for other potential exploration blocks to ensure continuous cash inflow, which means $t$ in the equation is not a variable $\left(V_{t}=0\right)$, and the value of real options is only related to its price and the geology technology uncertainties.

The value of a deepwater project is defined as $V(Z, I)$ under perpetual operation, then the maximum project value with optimal output level satisfies the following requirement:

$\frac{1}{2} V_{Z Z} Z^{2} \sigma_{Z}^{2}+(r Z-C) V_{Z}+q V_{I}-q-(r+\lambda+\gamma) V=0$.

The boundary conditions are:

$$
\begin{aligned}
& V(0, I)=0 \\
& V_{Z}(0, I)=0 \\
& \lim _{Z \rightarrow \infty} V_{Z Z}(Z, I)=0 .
\end{aligned}
$$

Taking Eq. (21) together with Eq. (22) to establish the multi-factor real options model under conditions of uncertainty, and it is generally difficult to obtain analytical solutions for this model. A numerical simulation method is adopted instead for this model.

\section{Variable simulation and parameter analysis}

\subsection{Variable simulation}

In Sect. 2 the oil price, geological factor and technological factor are described by using stochastic differential equation (SDE), and the SDE is solved to get the key parameters of the equation. Also, the three factors are integrated together to build up the integration model. Figure 2 shows the simulation results of the factors based on the SDE and the Gauss fitting result.

We collect 1500 WTI (West Texas Intermediate) weekly oil price data and fit these data for comparison analysis, as shown in Fig. 3.

Figures 2 and 3 indicate that the simulated movements and actual oil price movements share the same characteristics of stochastic process if excluding unpredictable sudden jumps caused by political or economic emergencies. Therefore, the above simulation model and the given values acquired successfully to reflect the characteristics of 

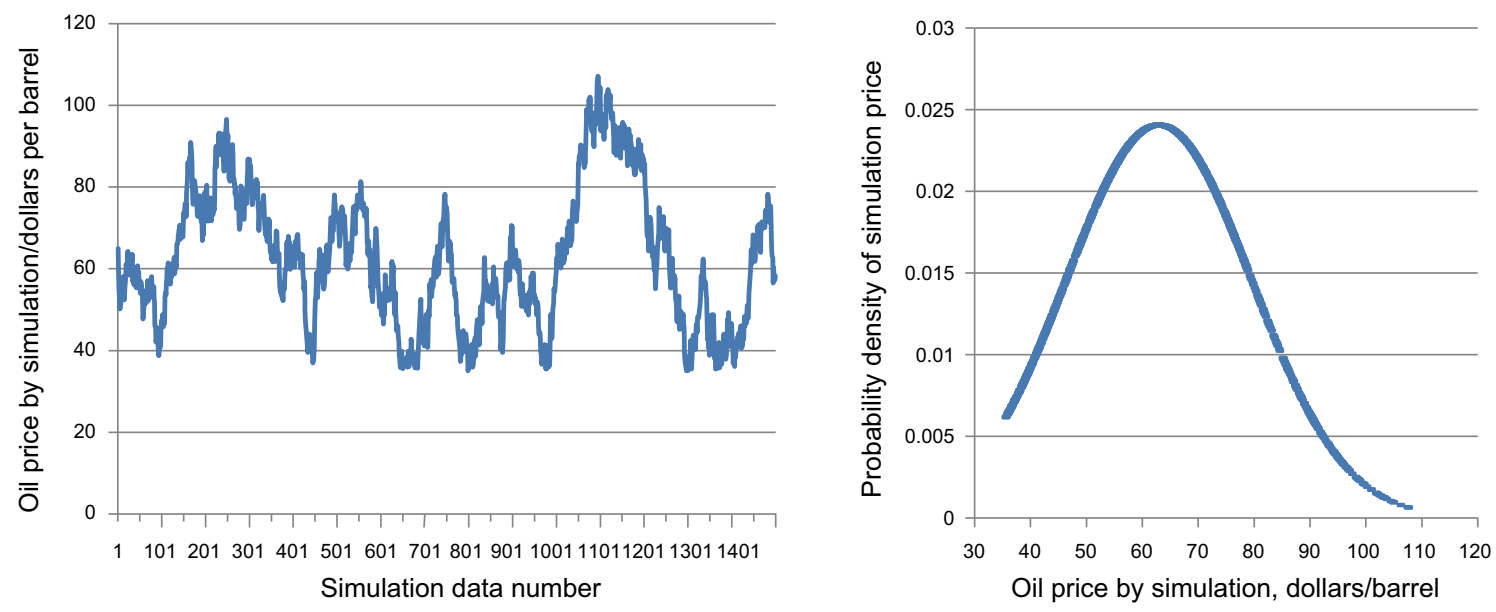

Fig. 2 The stochastic simulation and Gauss fitting of oil price

real oil price movements, and the basic form of the model conforms to a Wiener process, thus it can be used in financial models for oil and gas asset evaluation.

Simulation results of the geology technology factor $G$ and the integrated three factors are shown in Figs. 4 and 5 .

According to Figs. 2, 3, 4 and 5, the integration made in this work meets the hypothesis of Ito's lemma, and can be the basis of the parametric estimate in the multi-factor real options model. In addition, the fitting results of integrated and single factors are different from each other, which also prove that the study for multi-factor real options model makes sense.

\subsection{Parameter analysis}

Wang and Li (2010) analyzed the parameters of the real options model and demonstrated the significant influence of the parameters to the valuation result. In order to make the multi-factor real options model applicable, accurate and understandable, study of the parameters value must be first conducted. Deepwater oil and gas exploration and development projects involve interests of many parties, which are stipulated in complicated contract clauses. The study of convenience yield is computed based on these clauses, which is analyzed in the research by Liu et al. (2012).

\subsubsection{Investment rate and its influence on project value}

In deepwater oil and gas exploration projects, investors are confronted with many uncertain factors, which on the other hand provide them with great flexibility in project management: they can expand or hold down the investment volume according to updated geological and technological conditions, and increase or reduce their
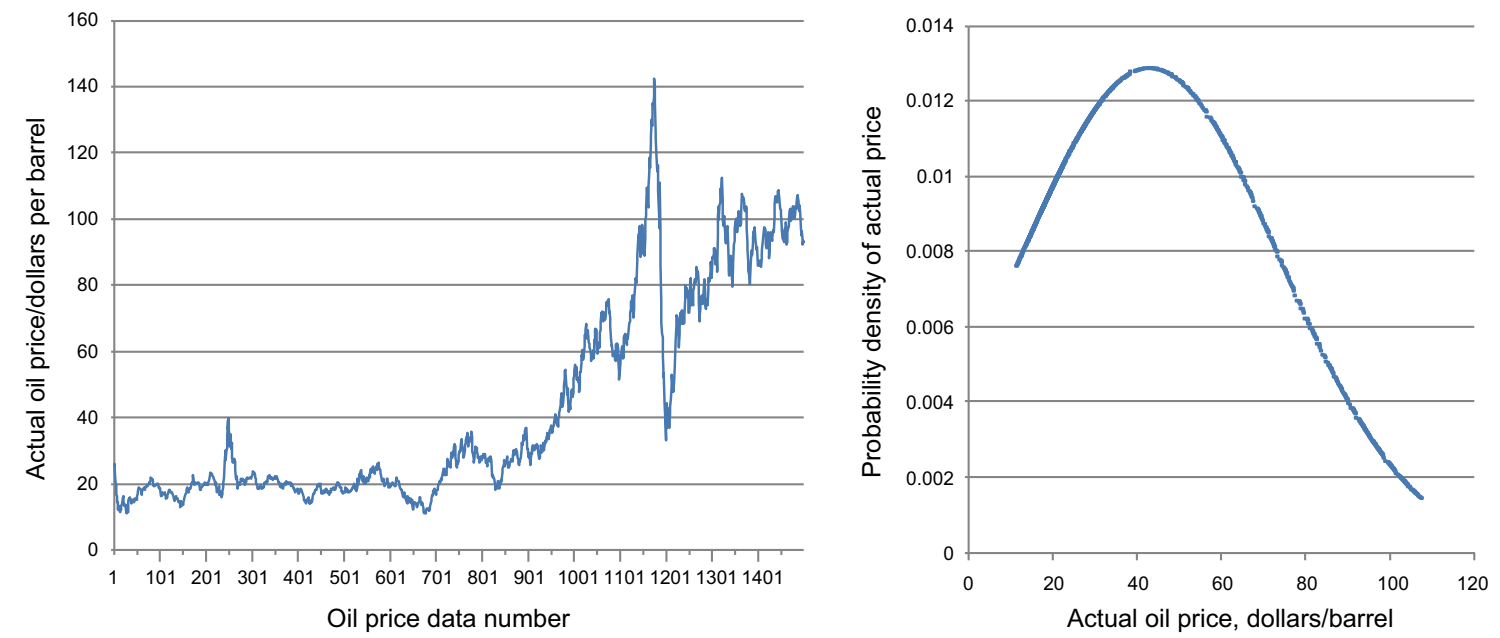

Fig. 3 The plot and Gauss fitting of WTI oil price 

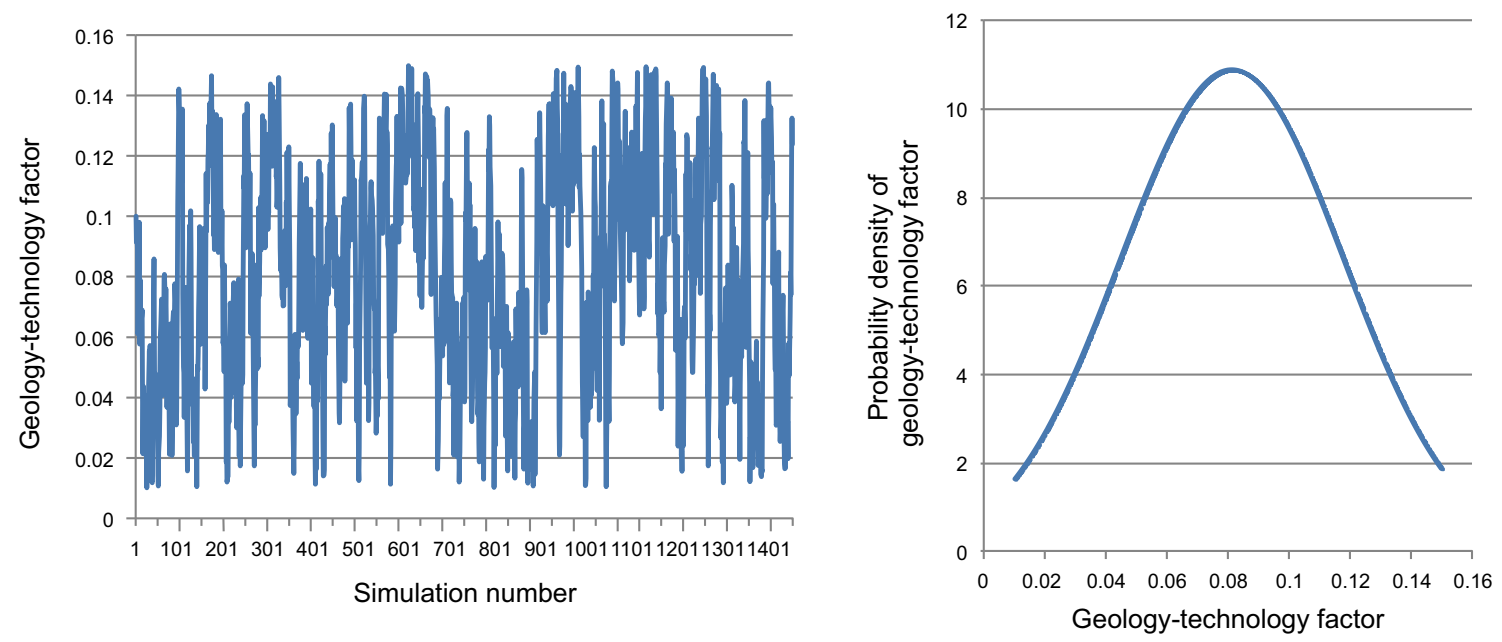

Fig. 4 The stochastic simulation and Gauss fitting of geology technology factor
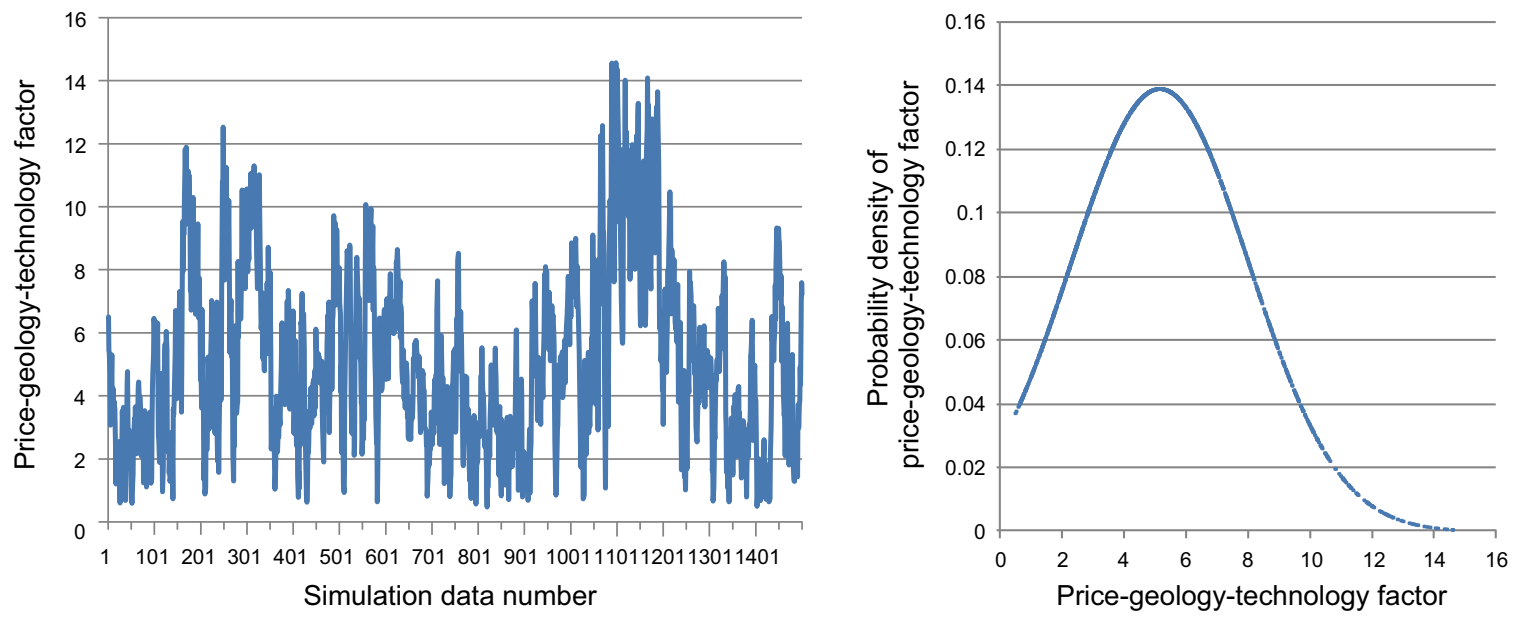

Fig. 5 The stochastic simulation and Gauss fitting of oil price-geology technology factor

production in consistence with market dynamics. Whereas there is one thing in common for most projects: some of the investment is irreversible despite succeeding investment policies as the initial investment is sunk or at least partially sunk. The investment in exploration is totally irreversible no matter if it succeeded or failed in finding recoverable resources.

The investment rate in exploration indicates the capital expenditure in search of recoverable oil and gas resources, and it is a crucial factor for total investment returns in the real options evaluation model. When oil companies increase their investment in exploration, they will acquire information about recoverable reserves with higher volume and better accuracy, and they will also have more confidence to realize greater economical value of the project. Thus it is reasonable to assume that the increase in exploration investment adds value to the project. To be more simplified, we suppose the exploration investment and project value are in positive linear correlation.

\subsubsection{Success rate in exploration}

Success rate in exploration changes with many factors such as location, reservoir conditions, exploration engineering and equipment, and oil companies have different success rates in their exploration works in different areas and different blocks. It is fairly difficult to calculate or predict with limited geology and engineering information, while an alternative is to use empirical values from 
projects with similar location, water depth and other parameters.

\subsubsection{Convenience yield rate}

Convenience yield rate is a sensitive parameter in a real options evaluation model. Gibson and Schwartz (1990) suggested that convenience yield was the value-added cash flow naturally derived from products, and it belonged to the holders of such products rather than holders of derivative contracts; Convenience yield depended on the volume of inventory: products of less inventory and higher spot price could achieve higher convenience yield, and vice versa. Paddock et al. (1988) concluded that investment return of developed reserves consisted of two parts: operating profits from production sales and capital gains from intrinsic value growth of remaining reserves. Thus let convenience yield be:

$C_{t}=\frac{\omega\left[\Pi_{t}-V_{b t}\right]}{V_{b t}}$

where $\omega$ is the decline rate of production in percentage; $\Pi_{t}$ is after-tax profit of oil sales; $V_{b t}$ is oil value of developed reserves per barrel.

\subsubsection{Market investment return}

We can adopt the return of investment used in discounted cash flow analysis and adjust it according to the characteristics of assets in the same region.

Table 1 Parameter estimation

\begin{tabular}{lc}
\hline Market price of developed reserves $V_{b}, \$ / \mathrm{bbl}$ & 15.38 \\
After-tax earnings $\Pi, \$ / \mathrm{bbl}$ & 19.01 \\
Total cost $D, \$ / \mathrm{bbl}$ & 13.04 \\
Exploration cost $E, \$ / \mathrm{bbl}$ & 2.96 \\
Influence of investment changes to project value $V_{I}$ & 1.9 \\
Success rate in exploration $\gamma$ & 0.2 \\
Production decline rate $\omega, \%$ & 6.25 \\
Investment rate $q, \%$ & 23.00 \\
Market investment return $r, \%$ & 10.00 \\
Convenience yield $C, \%$ & 1.50 \\
\hline
\end{tabular}

\section{Evaluation and decision analysis}

An overseas deepwater asset located in West Africa is an example for this multi-factor real options model. This project is under a production-sharing contract (PSC). At the initial stage of investment, the oil price was at a relatively low level but moving upward, so the exploration scheme was conservatively designed for modest oil production since only pre-exploration had been conducted, and detailed exploration data were not available. At the initial decision point, the discounted cash flow analysis did not show too much promise even though adjacent oil blocks showed promising economic returns. So the decision making of this project does not completely refer to DCF analysis results.

Parameters in the real options model are calculated (see Table 1) according to the contract and the analysis in Sect. 4.

Assume that oil price is at USD65\$ with volatility of 0.18 and factor $G$ equals 0.1 with volatility of 0.25 , then the value of this project with geology technology uncertainties amounts to USD13.53\$ per barrel. In a more pessimistic scenario with higher geology technology risks, assuming factor $G$ to be 0.07 , the evaluation result from the real options model suggests a project value of USD6.48\$ per barrel.

While a single-factor real options model is often applied to evaluate the flexibility value with uncertainties in oil price, this study adopts both multi-factor real options model and net present value method to better demonstrate the uncertainties. The comparison results are shown in Table 2 .

The results in Table 2 show that the multi-factor real options model can better reflect the flexibility value. Besides, projects in adjacent blocks are endowed with excellent geological conditions. They have exhibited great potential and gained much higher economic returns than their initial evaluation results, which provide evidence for the effectiveness of multi-factor real options model to some extent.

On the other hand, the results under higher geology technology risks scenario by a multi-factor real options model are much more conservative than those given by the single-factor model, thereby it confirms that multi-factor model is more capable in reflecting the impact of

Table 2 Results of three evaluation methods

\begin{tabular}{llllc}
\hline Evaluation method & NPV & $\begin{array}{l}\text { Single-factor real } \\
\text { options model }\end{array}$ & $\begin{array}{l}\text { Multi-factor real options } \\
\text { model with high } G \text { rate }\end{array}$ & $\begin{array}{l}\text { Multi-factor real options } \\
\text { model with low } G \text { rate }\end{array}$ \\
\hline Result, USD/barrel & 5.76 & 7.38 & 13.53 & 6.48 \\
Deviation from NPV result & - & $28.13 \%$ & $135 \%$ & $12.5 \%$ \\
\hline
\end{tabular}


engineering factors on projects' flexibility value while single-factor model only focuses on the impact of oil prices but ignores the impact of geology and technology.

\section{Conclusions}

The management of flexibility value is not only embodied in the feasibility to elevate the economic value of reserves by adjusting production to oil prices. It's also shown in the flexibility to design exploration schemes according to the uncertainty of geological information and technology, especially for deepwater oil and gas exploration projects. We analyzed several influential factors for project value with reference to the characteristics of real options in deepwater projects. We established a multi-factor real options model under uncertain conditions for project evaluation, and employed the idea of multi-uncertainty factors integration to make the model practical.

The model has been successfully applied to a real deepwater project. The evaluation result shows that the multi-factor real options model could be more accurate than the single-factor model. This multi-factor model gives investors more reliable theoretical supports to make reasonable decisions. Our sample project has been operated for more than five years, and the real practice has also showed that the estimated value with multi-factor real options model is a better approximation to reality. So the multi-factor real options model could be a good reference approach for investment decisions about deepwater oil and gas projects.

Acknowledgments The authors would like to thank the experts for their helpful discussion and suggestions on the 18th Annual International Conference on Real Options. This paper is supported from the National Science and Technology Major Project under Grant No. 2011ZX05030.
Open Access This article is distributed under the terms of the Creative Commons Attribution 4.0 International License (http://creativecommons.org/licenses/by/4.0/), which permits unrestricted use, distribution, and reproduction in any medium, provided you give appropriate credit to the original author(s) and the source, provide a link to the Creative Commons license, and indicate if changes were made.

\section{References}

Brennan MJ, Schwartz ES. Evaluating natural resource investments. J Bus. 1985;58(2):135-57.

Clapp R, Stibolt R. Useful measures of exploration performance. J Pet Technol. 1991;10:1252-7.

Cortazar G, Schwartz ES, Casassus J. Optimal exploration investments under price and geological-technical uncertainty: a real options model. R\&D Manag. 2001;31:181-9.

Dias MA. Valuation of exploration and production assets: an overview of real options models. J Pet Sci Eng. 2004;44:93-114.

Dixit AK, Pindyck RS. Investment under uncertainty. Princeton: Princeton University Press; 1994.

Fan Y, Zhu L. A real options based model and its application to China's overseas oil investment decisions. Energy Econ. 2010;32:627-37.

Gibson R, Schwartz ES. Stochastic convenience yield and the pricing of oil contingent claims. J Financ. 1990;45(3):959-76.

Itō K. Stochastic process. Beijing: Postal and Telecom Press; 2010 (in Chinese).

Itō K. Probability theory. Beijing: Postal and Telecom Press; 2011 (in Chinese).

Liu M, Wang Z, Zhao L, et al. Production sharing contract: an analysis based on an oil price stochastic process. Pet Sci. 2012;9(3):408-15.

Myers SC. Determinants of corporate borrowing. J Financ Econ. 1977;5(2):147-75.

Schmit TM, Luo J, Conrad JM. Estimating the influence of U.S. ethanol policy on plant investment decisions: a real options analysis with two stochastic variables. Energy Econ. 2011;33:1194-205.

Paddock JL, Seigel DR, Smith JL. Option valuation of claims on real assets: the case of offshore petroleum. Q J Econ. 1988;103(3):479-508.

Wang Z, Li L. Valuation of the flexibility in decision-making for revamping installations: a case from fertilizer plants. Pet Sci. 2010;7(3):428-34. 